\title{
High community burden of smoke-related symptoms in the Hunter and New England regions during the 2019-2020 Australian bushfires
}

\section{Zachary L Howarda,b,e, Sandra J Carlson"a, Zoe Baldwina, Fay Johnstonc, David N Durrheimª,d and Craig B Daltona,d}

a Population Health, Hunter New England Local Health District, Newcastle, NSW, Australia

b Hunter Medical Research Institute, Newcastle, NSW, Australia

c Menzies Institute for Medical Research, University of Tasmania, Hobart, Australia

'School of Medicine and Public Health, University of Newcastle, NSW, Australia

e Corresponding author: zach.howard@uwa.edu.au

\section{Article history}

Publication date: December 2020

Citation: Howard ZL, Carlson SJ, Baldwin Z, Johnston F, Durrheim DN, Dalton CB. High community burden of smoke-related symptoms in the Hunter and New England regions during the 2019-2020 Australian bushfires. Public Health Res Pract. 2020;30(4):e30122007. First published: 11 June 2020. https://doi.org/10.17061/ phrp30122007

\section{Introduction}

From October 2019 to February 2020, Australia was ravaged by bushfires. For large parts of the country, visible smoke and prolonged periods of elevated particulate air pollution (see Appendix 1, available from: osf. io/8z3ne/) became the norm, and resulted in community concern about the health impacts of bushfire smoke. Particulate matter from smoke is known to increase both mortality ${ }^{1}$ and hospitalisation risk. ${ }^{1,2}$ In New South Wales (NSW), Australia, there were increases in emergency presentations of respiratory illnesses during the smoke-affected period. ${ }^{3}$ However, these presentations comprise only the most serious cases of bushfire-related illness. Comparatively little is known about the lower levels of the burden-of-illness pyramid (a way of categorising illness from mild through to severe) - that is, what proportion of the community was affected by smoke but did not present to health services? Typical health surveillance systems are likely to miss these cases; as a result, if the majority of smoke-related illness is mild, the true health impact of the bushfires is likely to be severely underestimated.

\section{Methods}

We adapted the Flutracking surveillance system ${ }^{4}$ to provide insight into the community burden of smoke-related symptoms in the Hunter and New England regions of NSW. Flutracking is a weekly, email-based surveillance system for influenza-like illness, which involves more than 50000 participants across Australia who voluntarily self-report on influenza-like symptoms during the winter months. These participants represent a cohort who are motivated to answer surveys on health-related issues. Participants provide a postcode upon sign-up, so that geographically targeted investigations are possible. 
One person per household responds to surveys for all household members in the Flutracking database (this person is termed the 'respondent'). Household members are usually added on enrolment to Flutracking, but can be added throughout the season (respondents plus household members equals 'participants'). Flutracking can also send targeted, one-off surveys to any respondent in the cohort.

To rapidly assess the health impacts of bushfire smoke, we sent a one-off survey to a randomly selected group of past respondents from the Hunter New England Local Health District (HNE), an area known to have high levels of smoke and particulate concentrations during the survey period 2-15 December 2019 (see Appendix 1, available from: osf.io/8z3ne/), and the health district where Flutracking is based. To overcome the lack of historical baseline data, we also selected a control group from Hobart, Tasmania, which did not show elevated particulate concentration during the survey period. We randomly selected 1200 past respondents per location (Hobart and HNE) to receive the survey; these respondents were drawn from all active Flutracking respondents in those locations as at 15 December 2019 (location determined by registered postcode). This resulted in a total participant pool of 2293 for HNE and 2077 for Hobart, including household members. The survey was sent by email at 3 pm on 16 December 2019 (see Appendix 2 for full questionnaire, available from: osf. io/8z3ne/). Note that not all questions are covered in this brief report.

\section{Results}

Within 4 hours of sending the survey, we received 1181 responses, highlighting the utility of Flutracking for rapid data collection in public health emergencies. By 27 December, we had received 2281 survey responses, including household members (1438 from HNE and 843 from Hobart). Of those surveys, 2043 indicated they were present at their regular address during the survey period, and were included in the final analysis (1286 from HNE and 757 from Hobart).

Participants in the HNE region were much more likely to have experienced at least one symptom (65.1\%, compared with $16.1 \%$ in Hobart; odds ratio [OR] 10.4; 95\% confidence interval $[\mathrm{Cl}]$ 8.3, 13.0; $p<0.001)$.

Figure 1. Percentage of participants reporting each symptom surveyed, by location and history of respiratory illness

No history of respiratory illness

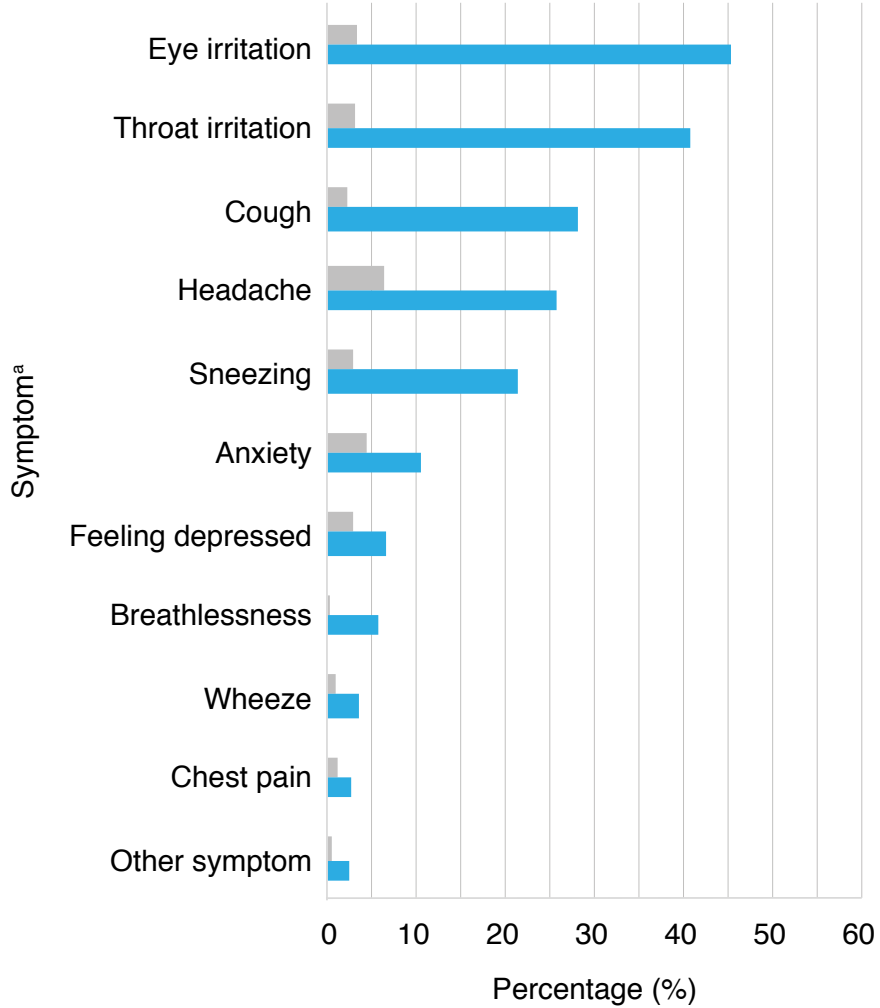

History of asthma or other respiratory illness

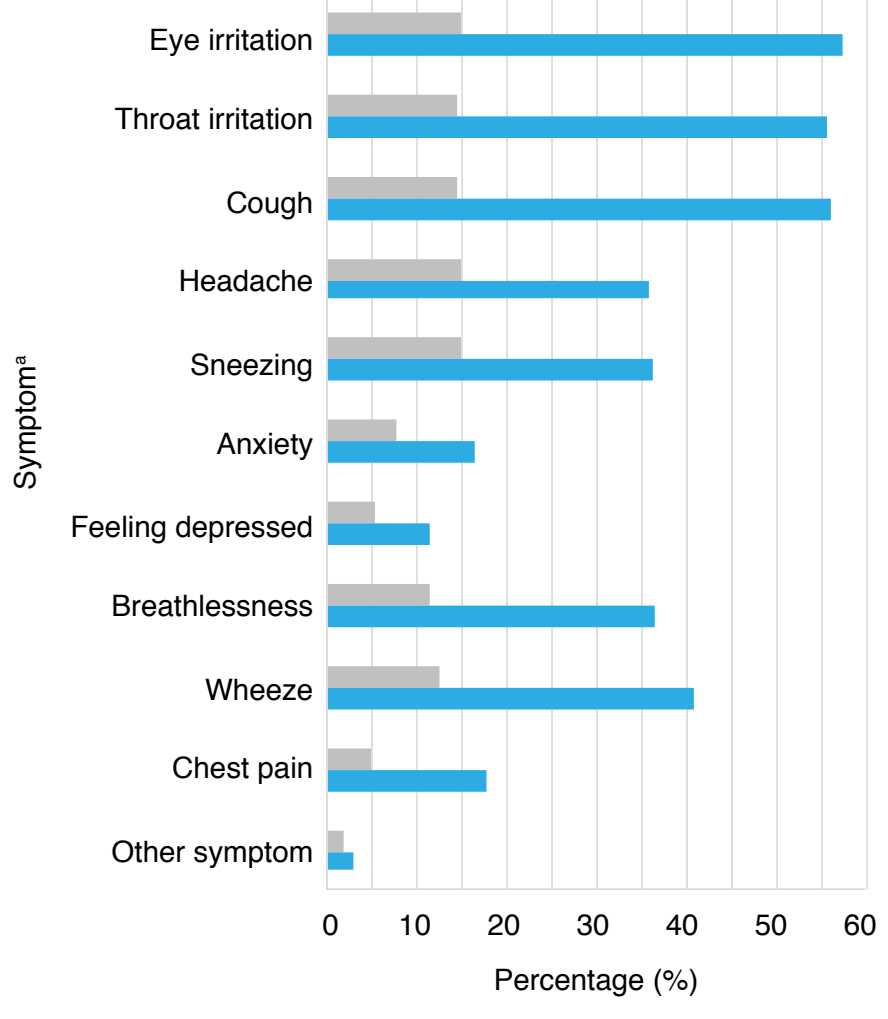

Hobart Hunter New England

a Participants could select any combination of symptoms. Data in this figure excludes participants who reported being out of their usual area of residence during most of the survey period.

Note: Both regions had comparable percentages of participants reporting a history of asthma or other respiratory illness (22.0\% in the Hunter New England region and 22.2\% in Hobart). 
The most prevalent symptoms in HNE participants were eye irritation, throat irritation, cough, headache and sneezing, consistent with previous smoke-related surveys $^{5}$ (Figure 1). Rates of eye and throat irritation were almost nine times higher in HNE than in Hobart. Participants in HNE who reported a history of asthma or other respiratory illness had higher overall symptom rates $(83.0 \%)$ than participants with no history $(60.0 \%$; OR 3.5; 95\% Cl 2.5, 5.0; $p<0.001$ ), including elevated levels of symptoms such as breathlessness, wheeze and chest pain (Figure 1). Of participants who reported symptoms, $87.5 \%(n=732)$ in HNE attributed at least one symptom to bushfire smoke, compared with 13.9\% ( $n=17$; OR 43.1; $95 \% \mathrm{Cl} 24.8,74.8 ; p<0.001$ ) in Hobart. Despite high symptom prevalence, only $10.3 \%$ of HNE participants who experienced a symptom reported seeking health advice.

\section{Discussion}

Our results show a high community burden of bushfire smoke-related symptoms - more than $56 \%$ of all participants in the HNE region experienced symptoms that they attributed to bushfire smoke. This is despite several shortcomings in the study, including the lack of historical symptom prevalence, a likely response bias, and a lower control group response rate. We caution against using this small survey to make inferences about the general population; however, the data clearly speak to the effects of bushfire smoke on immediate health outcomes.

Most of the participants experiencing symptoms did not seek advice from a medical practitioner, so would be missed by typical health service-based surveillance approaches. These data highlight the need to consider the whole burden-of-illness pyramid to better estimate the health impacts of public health emergencies, and the need for public health messaging about managing smokerelated symptoms during bushfires. The data also suggest that general practitioners should work with their patients with respiratory health issues (such as asthma) to develop management plans for bushfire scenarios.

Our study demonstrates the utility of Flutracking as a rapid assessment tool in public health emergencies. We provided a snapshot of smoke-related illness within 1 week of study conceptualisation. Such data (on a national scale) could prove invaluable for planning public health responses to future crises.

\section{Competing interests}

None declared.

\section{Author contributions}

$\mathrm{ZH}$ led the manuscript preparation and performed all analyses. FJ provided expert input on bushfire-related illness and survey design. SC and ZB assisted manuscript preparation and study design. CD and DD supervised the project and provided expert medical input.

\section{References}

1. Liu JC, Pereira G, Uhl SA, Bravo MA, Bell ML. A systematic review of the physical health impacts from nonoccupational exposure to wildfire smoke. Environ Res. 2015;136:120-32.

2. Horsley JA, Broome RA, Johnston FH, Cope M, Morgan GG. Health burden associated with fire smoke in Sydney, 2001-2013. Med J Aust. 2018;208(7):309-10.

3. NSW Government: Health. Sydney: Centre for Epidemiology and Evidence, NSW Ministry of Health; 2015. Rapid Surveillance using PHREDSS; 2017 March 7 [cited 2020 Jun 4]. Available from: www.health.nsw. gov.au/epidemiology/Pages/rapid-surveillance-usingPHREDSS.aspx

4. Moberley S, Carlson S, Durrheim D, Dalton C. Flutracking: weekly online community-based surveillance of influenzalike illness in Australia. 2017 annual report. Commun Dis Intell. 2019;43.

5. Kolbe A, Gilchrist KL. An extreme bushfire smoke pollution event: health impacts and public health challenges. N S W Public Health Bull. 2009;20(2):19-23.

\section{Peer review and provenance}

Externally peer reviewed, not commissioned.

\section{Copyright: (c) $1(3)$}

(C) 2020 Howard et al. This article is licensed under the Creative Commons Attribution-NonCommercial-ShareAlike 4.0 International Licence, which allows others to redistribute, adapt and share this work non-commercially provided they attribute the work and any adapted version of it is distributed under the same Creative Commons licence terms. See: www.creativecommons.org/licenses/by-nc-sa/4.0/ 